\title{
Assessment of Lactic Dehydrogenase in Cerebrospinal Fluid to Differentiate Between Structural And Non-Structural Central Nervous System Lesions in Patients with Diminished Level of Consciousness.
}

\author{
${ }^{* 1}$ Dr.Yogesh Kumar, ${ }^{2}$ Dr.Jyoti Prakash Yogi, ${ }^{3}$ Dr.S. Banerjee \\ ${ }^{I}$ (Residents, Department Of Gen Medicine Sms Medical College/ Ruhs, Raj., India) \\ ${ }_{2}^{2}$ (Residents, Department Of Gen Medicine Sms Medical College/ Ruhs, Raj., India) \\ ${ }_{3}^{3}$ (Sen. Prof. \& Unit Head, Department Of Gen Medicine Sms Medical College/ Ruhs, Raj., \\ India) \\ *Corresponding author: Dr.Jyoti Prakash Yogi*
}

\begin{abstract}
Although both metabolic and structural abnormalities have devastating effect on the CNS, their treatment approaches and prognoses vary considerably. This study was conducted among 53 patients with diminished level of consciousness and CSF was analyzed for quantitative $L D H(I U / L)$ value. In our study mean CSF-LDH was $25.19+12.92$ in patients with non-structural lesion and $86.53+32.09$ in patients with structural lesion of brain and difference was statistically highly significant $(p<0.001)$. So CSF-LDH values can be used to differentiate between patients with structural pathology and those with metabolic disturbances.
\end{abstract}

Keywords: lactic dehydrogenase (LDH); diminished level of consciousness; cerebrospinal fluid; non-structural lesion; structural lesion

\section{Introduction}

Acute impairment of consciousness is a common reason for emergency department admission.Causes of diminished level of consciousness ${ }^{1,2}$ include structural (like trauma, intracranial haemorrhage, tumor, hydrocephalus, epilepsy, meningitis ,encephalitis, cerebral venous thrombosis etc.) and non-structural\{ like metabolic ( including hyponatremia, hypocalcemia, hypomagnesemia, ketoacidosis, hypoglycaemia)\}, hepatic failure, uremia, hypercapnea, hypothyroid, hypertension, hypothermia, infections and drugs. Damage within the central nervous system results in raised values of intracellular products within the cerebrospinal fluid considerably earlier than they can be detected in the bloodstream. Although many studies have demonstrated an increase in the concentration of creatine kinase, LDH, and glutamic oxaloacetic transaminase from 8 hours to several days after the onset of stroke,LDH was found to be the most sensitive CSF enzyme in indicating cerebrovascular events. ${ }^{3-6,8}$. A significantly increased CSF-LDH level has been demonstrated in patients with hemorrhagic infarcts, mild and moderate strokes, small lacunar infarcts, and even transient ischemic attacks. ${ }^{4}$ Normal CSF-LDH level are $\leq 70$ units/L for newborns and $\leq 40$ units/L for adults. ${ }^{6,9}$

\section{Problem Definition And Literature Survey-}

Although the Glasgow Coma Scale (GCS) score is used to analyse physical findings in patients with altered consciousness, but it cannot discriminate between structural and non-structural etiologies. ${ }^{1,2}$ Computed tomography (CT) of the brain is a key diagnostic tool in these cases, though it may be inconclusive in some patients with coma or delirium and also it may not be readily available in many parts of the world. ${ }^{7}$ Wroblewski et al first described the clinical importance of elevated spinal fluid LDH in 1957. In 2008, Vazquez et al showed spinal fluid LDH level bellow40 units/liter in adult critically ill patients with non traumatic altered mental status is indicative of a metabolic derangement ${ }^{(9)}$. To determine CSF-LDH values that may differentiate between patients with structural pathology and those with metabolic disturbances, we designed a study to quantitatively analyzed the enzyme in patients with impaired consciousness.

\section{Material And Methods}

This prospective observational, cross-sectional study was conducted among 53 patients with diminished level of consciousness without history of trauma from July 2012 to June 2013in Medicine wards at S.M.S. Hospital, Jaipur. The study included all patients $>18$ years of age who had GCS $<12$ on admission(since all patients for the study were critically ill, the average GCS was much lower, with most being <11). Patients were excluded if a computed tomography scan showed contraindications to performing a lumbar puncture, if they had a coagulopathy, or if the CSF was xanthochromic or produced visible blood sediment after centrifuging. All patients had a CT-scan before a lumbar puncture was performed. The CSF was analyzed for 
quantitative $\mathrm{LDH}(\mathrm{IU} / \mathrm{L})$ value. The study population was divided into two groups depending on whether their diagnosis indicated a structural or non-structural abnormality. Patients demography in both cohorts were assessed for differences and each group was analyzed individually Unpaired Student's t test and Chi-Square test were used to determine statistical difference between variables. Pearson's coefficient was used to investigate the correlation between the two variables. Statistical significance was set at $\mathrm{P}$ value $\leq 0.05$.

\section{Results And Discussions-}

Table No.-1 Mean \pm Sd of CSF-LDH according to Lesion

\begin{tabular}{|l|l|l|l|l|}
\hline \multirow{2}{*}{} & \multicolumn{2}{|l|}{ Lesion } & p- value & Significance \\
\cline { 2 - 3 } & Non-structural & Structural & & \\
\hline $\begin{array}{l}\text { Mean }+ \text { Sd } \\
(\text { CSF-LDH })\end{array}$ & $25.19 \pm 12.92$ & $86.53 \pm 32.09$ & $<.001$ & HS \\
\hline
\end{tabular}

Table1 explains mean CSF-LDH, which was $25.19 \pm 12.92 \mathrm{IU} / \mathrm{L}$ in patients with non-structural lesion and $86.53 \pm 32.09 \mathrm{IU} / \mathrm{L}$ in patients with structural lesion. Mean of CSF-LDH in 53 patients of study was $46.61 \pm 17.35$ IU/L. Difference of mean CSF-LDH between structural and non-structural lesion was statistically highly significant $(\mathrm{p}<0.001)$.

Table No.-2 Distribution according to CSF-LDH \& Lesion

\begin{tabular}{|c|c|c|c|}
\hline \multirow{2}{*}{ CSF- LDH } & \multicolumn{2}{|l|}{ Lesion } & \multirow{2}{*}{ Total } \\
\hline & Non-structural & Structural & \\
\hline $\begin{array}{l}\text { Abnormal } \\
(>40 \mathrm{IU} / \mathrm{L})\end{array}$ & $\begin{array}{l}1 \\
(1.89 \%)\end{array}$ & $\begin{array}{l}28 \\
(52.83 \%)\end{array}$ & $\begin{array}{l}29 \\
(54.72 \%)\end{array}$ \\
\hline $\begin{array}{l}\text { Normal } \\
(<40 \text { IU/L })\end{array}$ & $\begin{array}{l}20 \\
(37.74 \%)\end{array}$ & $\begin{array}{l}4 \\
(7.55 \%)\end{array}$ & $\begin{array}{l}24 \\
(45.28 \%)\end{array}$ \\
\hline Total & $\begin{array}{l}21 \\
(39.62 \%)\end{array}$ & $\begin{array}{l}32 \\
(60.38 \%)\end{array}$ & $\begin{array}{l}53 \\
(100,00 \%)\end{array}$ \\
\hline
\end{tabular}

Table2 shows that out of 29(54.72\%) patients with abnormal CSF-LDH(> 40 IU/L), 1(1.89\%) had nonstructural lesion and $28(52.83 \%)$ had structural lesion. Out of 24(45.28\%) patients with normal CSF-LDH( $<40$ IU/L), 20(37.74\%) had non-structural lesion and 4(7.55\%) had structural lesion. The association of CSF-LDH between structural and non-structural lesion was statistically highly significant $(\mathrm{p}<0.001)$.

\section{Conclusion}

In our study mean CSF-LDH was $25.19+12.92$ in patients with non-structural lesion and $86.53+$ 32.09 in patients with structural lesion of brain. Difference of mean CSF-LDH between structural and nonstructural lesion was statistically highly significant $(\mathrm{p}<0.001)$. Thus in addition to the various tests including history and clinical examination to differentiate between structural and non-structural lesion of the brain, raised CSF-LDH can also be an useful tool to diagnose a structural lesion of the brain.

\section{Future Scope}

The association of CSF-LDH between structural and non-structural lesion was statistically highly significant $(\mathrm{p}<0.001)$ as seen in our study. Thus it can be conveniently interpreted that significant increase in CSF-LDH was related to structural lesion of the CNS.

\section{Limitations}

Our study is limited by the fact that lumbar puncture and imaging studies were only done in patients that were able to tolerate these procedures clinically and unstable patients were excluded from the study. Other problem of this study was a wide range of valuesin the $95 \%$ confidence interval due to the low numberof patients recruited during the research period. However, other studies havefound results similar to ours $(9,10,11)$. Larger, multi-center studies may beneeded to more adequately assess the applicability ofemergency department obtained CSF-LDH as a clinical tool.

\section{References}

[1]. Kandel ER, Jessell, Thomas M.; Schwartz, James H. (2000). Principles of neural science. New York: McGraw-Hill. p. 901. ISBN 08385-7701-6. Retrieved 2008-07-03.

[2]. Porth C (2007). Essentials of Pahtophysiology: Concepts of Altered Health States. Hagerstown, MD: Lippincott Williams \& Wilkins. p. 835. ISBN 0-7817-7087-4. Retrieved 2008-07-03.

[3]. Zandbergen E, Hann R, Hijdra A. Systemic review of prediction of poor outcome in anoxic -ischemic coma with biochemical markers of brain damage. Int care med 2001;27:1661-7. 
[4]. Donnan GA, Zapf P, Doyle AE, Bladin PF, CSF enzymes in lacunar and cortical stroke. Stroke 1983;14:266-9.

[5]. Lutsar I, Halder S, Topman M, Talvic T. Enzymatic changes in the CSF in patients with infections of CNS. Actapaediatr 1994;83:1146-50.

[6]. Health EncyclopediaLactate Dehydrogenase (CSF) 2013 University of Rochester Medical Center Rochester, NY 14642 | 585-275URMC (8762)

[7]. Cucchiara BL, Kasner SE, Wolk DA, et al. Early impairment in consciousness predicts mortality after hemispheric ischemic stroke. Crit care med 2004;32:241-5.

[8]. Bryan Young G, Wang JT, Connoly JF. Prognostic determination in anoxic-ischemic and traumatic encephalopathies, J ClinNeurophysiol 2004;21:379-90.

[9]. Vázquez JA, AdducciMdelCetal.Lactic dehydrogenase in cerebrospinal fluid may differentiate between structural and non-structural central nervous system lesions in patients with diminished levels of consciousness.JEmerg Med. 2009 Jul;37(1):93-7. Epub 2008 Nov 7.

[10]. Nand N, Gupta S, Sharma M, Khosla SN, Saini AS, Lal H. Evaluation of enzymes in serum and cerebrospinal fluid in cases of cerebrovascular accidents. Angiology1987;38:750-5.

[11]. 10. Sharma M, Nand N. Evaluation of enzymes in pyogenic and tuberculous meningitis. J assoc physicians india 2006;54:118-21. 